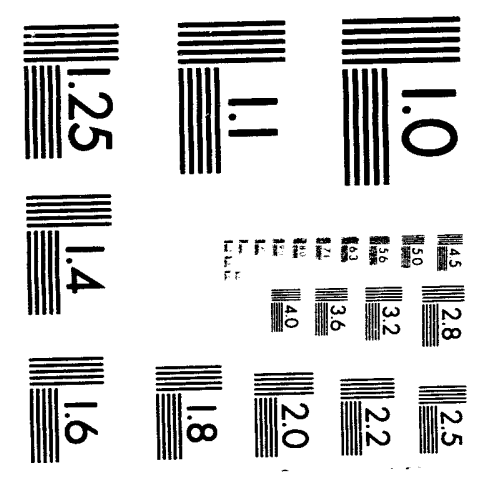



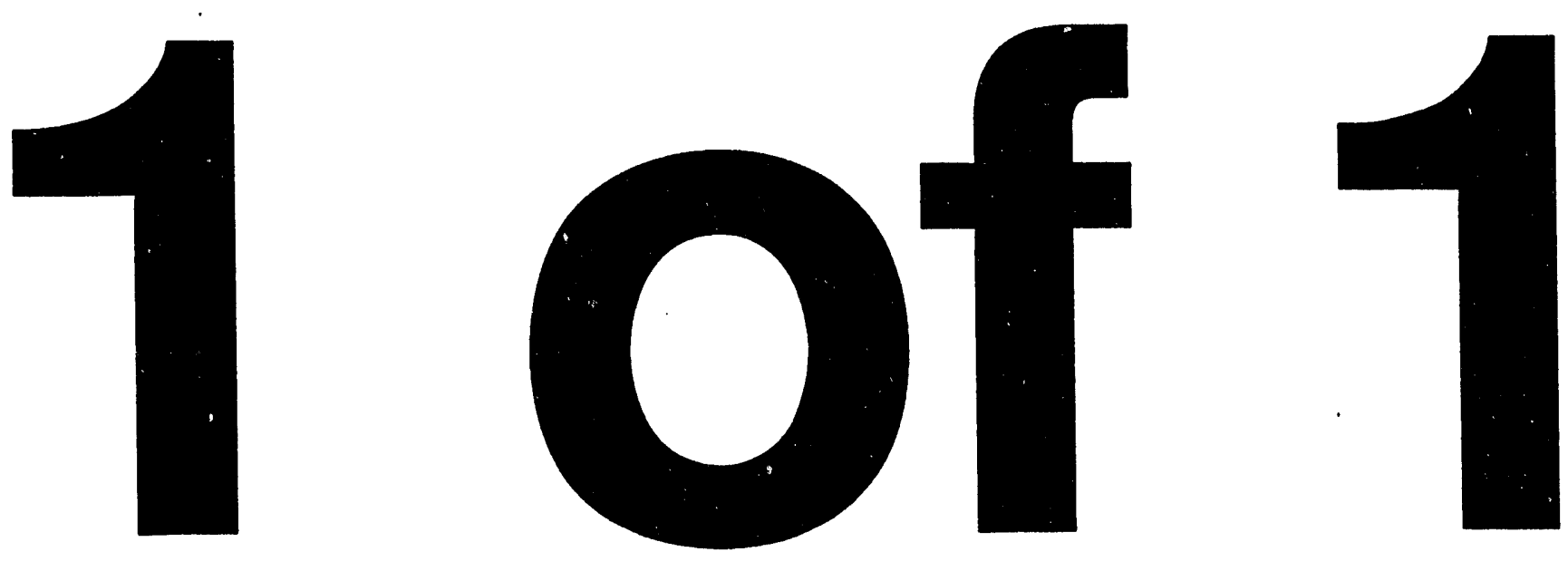


\section{MODELING URANIUM SOLUBILITY IN AGED VAULT DISPOSAL (U)}

by

E. G. Orebaugh

Savannah River Site

Aiken, South Carolina 29808

DOE Contract No. DE-AC09-89SR18035

This paper was prepared in connection with work done under the above contract number with the U. S.

Department of Energy. By acceptance of this paper, the publisher and/or recipient acknowledges the U. S. Government's right to retain a nonexclusive, royalty-free license in and to any copyright covering this paper, along with the right to reproduce and to authorize others to reproduce all or part of the copyrighted paper.

$$
\text { a. }
$$




\section{DISCLAIMER}

This report was prepared as an account of work sponsored by an agency of the United States Government. Neither the United States Government nor any agency thereof, nor any of their employees, makes any warranty, express or implied, or assumes any legal liability or responsibility for the accuracy, completeness, or usefulness of any information, apparatus, product, or process disclosed, or represents that its use would not infringe privately owned rights. Reference herein to any specific commercial product, process, or service by trade name, trademark, manufacturer, or otherwise does not necessarily constitute or imply its endorsement, recommendation, or favoring by the United States Government or any agency thereof. The views and opinions of authors expressed herein do not necessarily state or reflect those of the United States Government or any agency thereof.

This report has been reproduced directly from the best available copy.

Available to DOE and DOE contractors from the Office of Scientific and Technical Information, P. O. Box 62, Oak Ridge, TN 37831; prices available from (615) $576-8401$.

Available to the public from the National Technical Information Sirvice, U. S. Department of Commerce, 5285 Port Royal Rd., Springfield, VA 22161 
SAVANNAH RIVER TECHNOLOGY CENTER

WESTINGHOUSE SAVANNAH RIVER COMPANY

\author{
WSRC-RP-93-1318 \\ Keywords: Uranium \\ thermo dynamic \\ CC: W.F. Stevens, 773-A \\ J.R. Cook, 773-43A \\ E.I. Wilhite, 773-43A \\ R.A. Hiergesell, 773-43A \\ A.D. Yu, 773-43A \\ SRT'C Records (4)
}

September 9, 1993

$\begin{array}{ll}\text { To: } & \text { R.H. Hsu, 773-43A } \\ \text { From: } & \text { E.G. Orebaugh, } 773-43 A\end{array}$

MODELING URANIOM SOLUBILITY IN AGHD VAULT DISPOSAL (0)

Using Version 3.0 of the ESP software from OLI systems containing thermo dynamic data for uranium in the expanded data base, I have modeled the uranium solubility with the highest degree of accuracy avallable considering the limitations of the model. Uranium solubility in most oxic environments is taken to be complete, i.e. all the uranilum present is present as soluble uranyl salts at low concentrations. However, in modeling the chemistry of aged waste disposed in TRU vaults it is assumed that the organic components have been converted by aerobic and biological decay to an anoxic slurry and the steel waste containers have oxidized in part to a ferrous/ferric hydroxide slurry. The solubility modeling is valid only in anoxic regions where the redox potential is controlled by the ferrous/ferric couple. The redox behavior of the organics and biological activity are not addressed, but would only decrease the solubility further at $\mathrm{pH}<8$ where some uranyl species contribute to the overall solubility. By contrast, the calculated solubility due to carbonate complexes at $\mathrm{pH}<7$ could be low since the available carbonate in solution is not controlled by the solubility of $\mathrm{CaCO} 3$ until $\mathrm{pH} 7$ is attained.

Table 1 contains concentration data for the major species of $U(I V)$ and $U(V I)$ determined by the ESP data base and equilibrium calculations at $\mathrm{pH} 4-8$. In each case there were initially equal amounts (1.00E-6 Molar) of U(IV) and $\mathrm{U}(\mathrm{VI})$ and equal amounts (1.00E-4 Molar) $\mathrm{Fe}$ (II) and $\mathrm{Fe}$ (III). 
The following redox equation was used to describe these two redox couples:

$$
\mathrm{OO}_{2}{ }^{2+}+2 \mathrm{Fe}^{2+}+4 \mathrm{~B}^{+} \Leftrightarrow==\mathrm{O}^{+4}+2 \mathrm{Fe}^{+3}+2 \mathrm{~B}_{2} \mathrm{O}
$$

In acid medium ferrous ion is incapable of reducing uranyl salts, but at higher pHs the low solubility of Fe(III)and U(IV) combine to form a product sink which drives the reaction to near completion by $\mathrm{pH} 8$. Above $\mathrm{pH} 8$ the solubility is controlled almost entirely by U(IV) (OH) 4 aq in equilibrium with $\mathrm{UO}_{2} \times t a l$. These effects are clearly indicated graphically in Figures 1 and 2 which present the total solubility and speciation of this solubility as a function of $\mathrm{pH}$. 
TABIE I

U Speciation as a Function of $\mathrm{pH}$

\begin{tabular}{|c|c|c|c|c|c|}
\hline$\overline{\text { Species/pH }}$ & 4.0 & 5.0 & 6.0 & 7.0 & 8.0 \\
\hline UO2 solids & 0 & 0 & $1.977 E-6$ & 1.999E-6 & $2.000 E-6$ \\
\hline$U(I V)$ ion & 0 & 0 & 0 & 0 & 0 \\
\hline $\mathrm{U}(\mathrm{OH}) 1$ ion & 0 & 0 & 0 & 0 & 0 \\
\hline $\mathrm{U}(\mathrm{OH}) 2$ ion & 0 & 0 & 0 & 0 & 0 \\
\hline $\mathrm{U}(\mathrm{OH}) 3$ ion & $1.12 \mathrm{E}-20$ & 0 & 0 & 0 & 0 \\
\hline $\mathrm{U}(\mathrm{OH}) 4$ ion & $8.39 E-18$ & 3. $38 E-12$ & $3.04 \mathrm{E}-10$ & $3.04 E-10$ & $3.04 \mathrm{E}-10$ \\
\hline $\mathrm{U}(\mathrm{OH}) 5$ ion & 0 & $2.11 \mathrm{E}-17$ & $1.89 \mathrm{E}-14$ & $1.83 E-13$ & $3.68 \mathrm{E}-17$ \\
\hline su (IV) sol. & $8.40 E-18$ & 3. $38 \mathrm{E}-12$ & $3.04 \mathrm{E}-10$ & $3.04 \mathrm{E}-10$ & $3.04 \mathrm{E}-10$ \\
\hline $\mathrm{U}(\mathrm{VI}) \mathrm{O}_{2}$ ion & $1.91 E-6$ & $7.68 E-7$ & $7.64 \mathrm{E}-11$ & $3.43 E-16$ & $3.39 E-21$ \\
\hline $\mathrm{U}(\mathrm{VI}) \mathrm{O}_{2} \mathrm{OHion}$ & $6.96 E-8$ & $2.81 E-7$ & $2.79 E-10$ & 1. $36 \mathrm{E}-14$ & 1. $62 \mathrm{E}-18$ \\
\hline $\mathrm{U}(\mathrm{VI}) \mathrm{O}_{2} \mathrm{CO}_{3}$ & 2. $31 E-8$ & $9.19 E-7$ & $8.24 E-9$ & 1. $32 E-12$ & $6.01 E-17$ \\
\hline $\mathrm{U}(\mathrm{VI}) \mathrm{O}_{2}\left(\mathrm{CO}_{3}\right)_{2}$ ion & $1.42 E-9$ & $1.73 E-8$ & $1.39 E-8$ & $6.37 E-11$ & $7.86 E-15$ \\
\hline SU (VI) sol. & $2.00 E-6$ & $1.98 E-6$ & $2.24 \mathrm{E}-8$ & $6.50 E-11$ & $7.93 E-15$ \\
\hline Total 0 sol & $2.00 z-6$ & $1.98 \mathrm{E}-6$ & $2.27 \mathrm{E}-8$ & $3.69 \mathrm{~F}-10$ & $3.04 \mathrm{~F}-10$ \\
\hline
\end{tabular}

The speciation presented in table I results from calculations based upon thermodynamic data complled at Lawrence Berkeley Laboratory by Phillips et al. and published as "Thermodynamic Tables for Nuclear Waste Isolation, Aqueous Solution Database" NUREG/CR-4864, 1988 page 138. 
WSRC-RP-93-1318

September 9, 1993

Page 4

ORANIUM SPECIATION

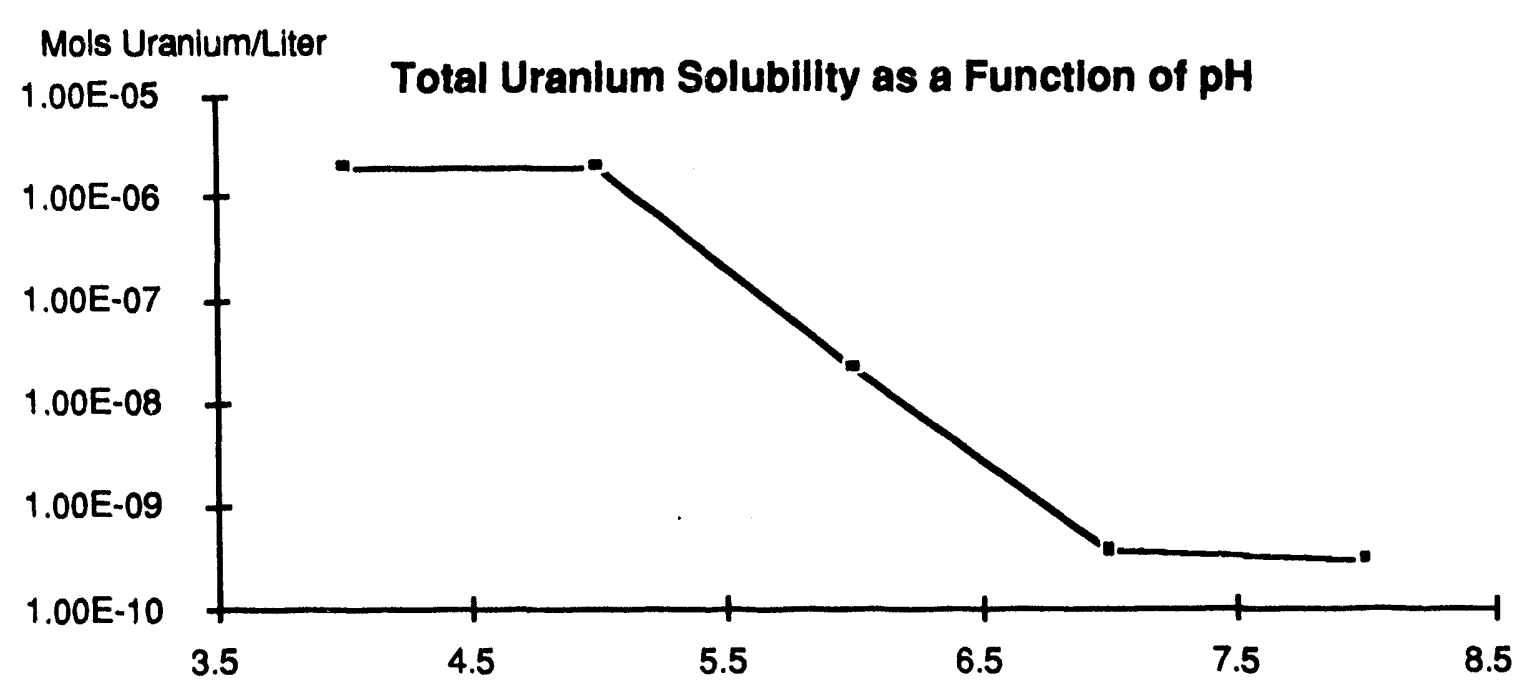

Figure 1 Solubility of 2 micromolar uranium as a function of $\mathrm{pH}$.

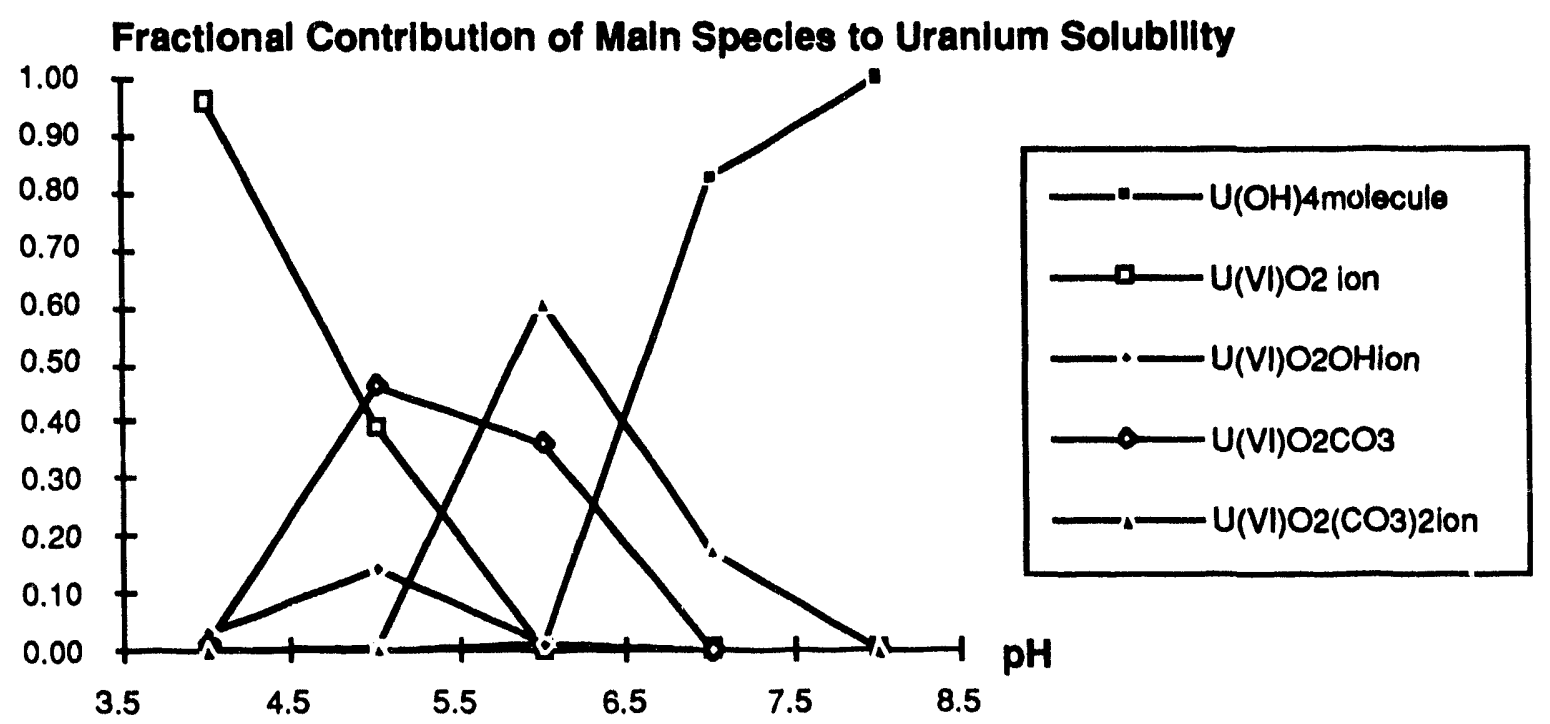

Figure 2 Speciation of soluble uranium as a function of $\mathrm{pH}$. 

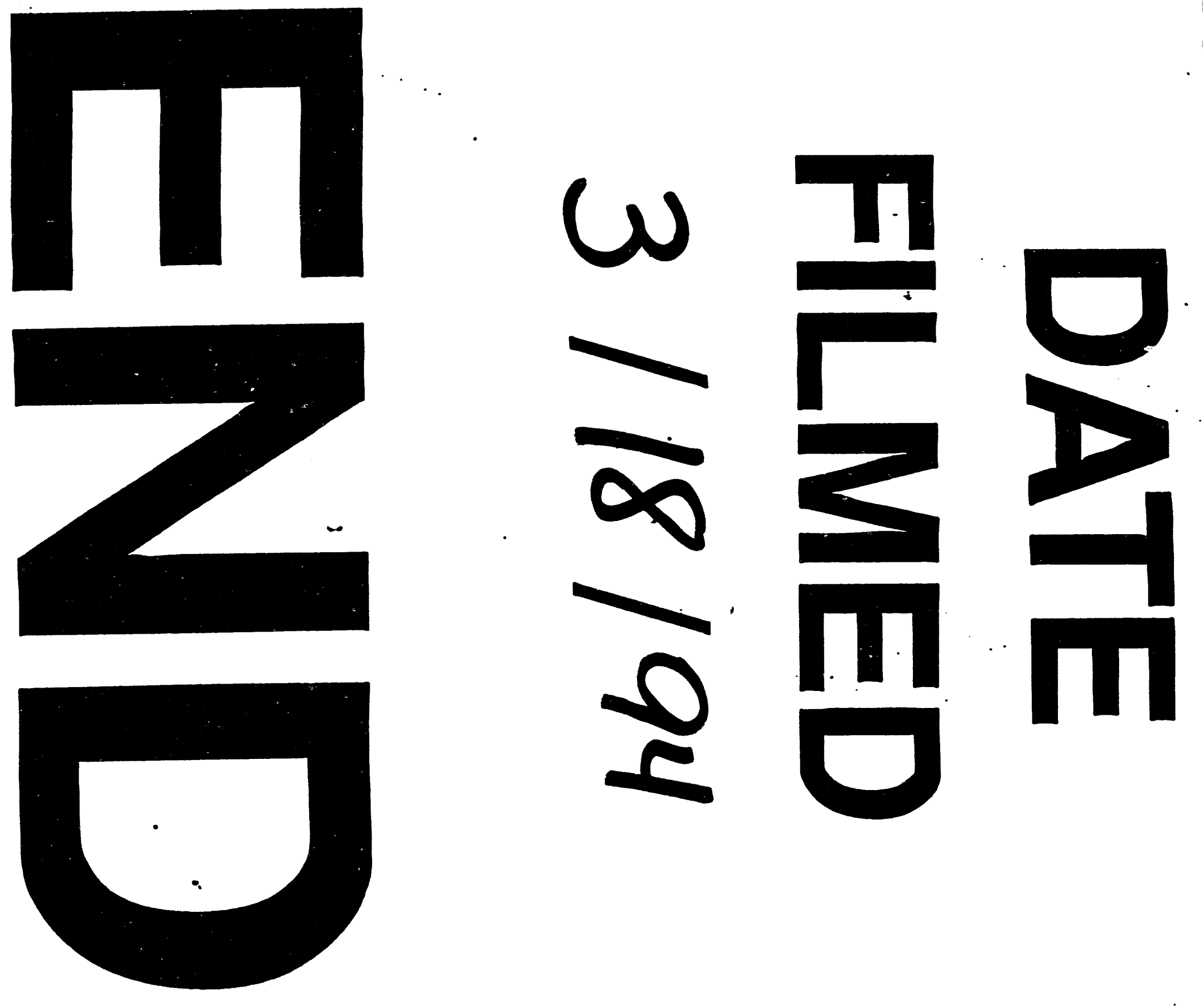
$=$ 